\title{
Review Article \\ Idiopathic Short Stature: Conundrums of Definition and Treatment
}

\author{
Arlan L. Rosenbloom \\ Department of Pediatrics, Children's Medical Services Center, University of Florida College of Medicine, 1701 SW 16 th Ave, \\ Gainesville, FL 32608, USA \\ Correspondence should be addressed to Arlan L. Rosenbloom, rosenal@peds.ufl.edu
}

Received 6 November 2008; Revised 24 January 2009; Accepted 11 February 2009

Recommended by Myron Genel

Children with idiopathic short stature (ISS) are statistically defined by height SDS $<-2$ for their bone age and should be distinguished from children with familial short stature for whom height SDS corresponds to mean parental SDS and from the most common explanation for short stature referred to pediatric endocrinologists, constitutional delay in growth and maturation (CDGM), in which there is normal height for bone age and predicted normal adult stature. Low IGF-I levels reported in ISS may be the result of subtle undernutrition or reference to standards appropriate for chronologic age but not osseous maturation in CDGM inappropriately labeled as ISS. While growth hormone (GH) treatment of ISS may add 4-5 cm to adult height, metaanalysis indicates that there is no documented evidence that such treatment improves health related quality of life or psychological adaptation. Thus, the estimated cost of US\$52 000/inch gained is difficult to justify. Absence of data regarding efficacy of the use of IGF-I for treatment of ISS has been noted in a recent consensus statement from the North American and European pediatric endocrinology societies. This report further emphasizes the importance of discouraging the expectation that taller stature from GH treatment will improve quality of life.

Copyright ( $\odot 2009$ Arlan L. Rosenbloom. This is an open access article distributed under the Creative Commons Attribution License, which permits unrestricted use, distribution, and reproduction in any medium, provided the original work is properly cited.

\section{What Is Idiopathic Short Stature?}

Short stature is often defined statistically as height less than -2 standard deviations (SD) of the age- and sex-matched population [1]. Such an arbitrary definition, however, would be inappropriate for the offspring of taller than normal or shorter than normal parents; a more appropriate definition for clinical purposes might be 2 SD below the mean parental SD score (SDS). Experienced clinicians have seen children with stunting conditions such as Turner syndrome not resulting in obvious short stature based on population because of tall parentage, and short stature meeting the population definition in children who are perfectly normal for their families [1]. Because stature in the population is a Gaussian distribution, some $2 \%$ of children will always be more than 2 SD below the mean for age and sex [2].

The issue is further complicated by wide variation in rates of maturation, such that a child may be short for age but not for osseous maturation. The definition of "idiopathic short stature" (ISS) should be appreciated in this context. The recent consensus statement on the diagnosis and treatment of children with idiopathic short stature defines ISS simply by height $>2$ SD below the corresponding mean height of a given age, sex, and population group without evidence of systemic, endocrine, nutritional, or chromosomal abnormalities, and normal stimulated growth hormone $(\mathrm{GH})$ levels [3]. It was noted that this definition included short children with constitutional delay in growth and maturation (CDGM) and those with familial short stature (FSS). While CDGM, which is often familial, and FSS are in a broad sense idiopathic, this inclusive classification obscures important diagnostic and treatment differences among the 3 entities. A child with ISS has a height SDS $<-2$ for his or her osseous maturation, and for mean parental height SDS. Such a child has an adult height prediction SDS $<-2$, and might be considered a candidate for growth therapy. The child with FSS will also be short for osseous maturation, as well as age, but as noted above, the height SDS will correspond to mean parental SDS. In such families, the short stature may be of less concern. The most common explanation for short stature 
in the pediatric endocrinology clinic is CDGM with normal stature for osseous maturation and normal adult height prognosis; this obviously dictates very different counseling and treatment consideration than ISS or FSS. Inconsistent with the classification of CDGM as ISS in the consensus document, specific treatment recommendations unique to CDGM were made [3]. These entities may overlap [1].

Subtle nutritional growth retardation, most frequently described in affluent communities due to self/family imposed dietary restriction, may be easily missed in the evaluation of short children $[1,4]$. Such marginal undernutrition and its lack of clinical manifestations or biochemical abnormalities can explain the shorter stature of earlier generations, and in those lacking critical micronutrients [5]. Approximately one half of German children with "ISS" were found to be poor eaters and to have lower body mass indices than normal [6].

Since the availability of unlimited supplies of recombinant human (rh) GH beginning in 1985, the definition of GHD has been greatly liberalized and has led to the inclusion and rhGH treatment of countless numbers of normal short children. This reflects the uncertainties of GH testing for the exclusion of GHD in children with ISS, FSS, or CDGM, including: assay variability; intraindividual variability; the arbitrary definition of normal; the influence of age, sex, pubertal status, and BMI on response; and deficient responses in the absence of endocrine disease (e.g., with undernutrition) and during the preadolescent growth lag phase. Furthermore, response to GH stimulation testing correlates with the success of GH treatment only when there is unequivocal deficiency. The unreliability of GH testing and the ease with which normal prepubertal children can be misdiagnosed as having GHD, was demonstrated among 84 normal children, using the relatively conservative criterion of GH concentration $\geq 7 \mathrm{ng} / \mathrm{mL}$ in response to treadmill and arginine-insulin stimulation. In those children who were at Tanner stage (TS) $4-5,100 \%$ met the criterion, while $89 \%$ of those at TS 3 did. Only $44 \%$ of TS 12 children, however, reached this criterion, but following ethinyl estradiol priming, $100 \%$ did. Using the commonly promoted criterion of $10 \mathrm{ng} / \mathrm{mL}, 94 \%$ of TS $4-5,77 \%$ of TS 3 , and only $23 \%$ of TS 1-2 children "passed." The obvious conclusion was that there is little value in GH testing of children at TS 1-3 unless they are primed with sex steroids [7]. This phenomenon probably accounts for the fact that $70 \%$ of patients treated for isolated GHD in childhood have normal GH responses when tested after adolescence [8].

The approval of the use of recombinant growth hormone (rhGH) for the treatment of ISS by the United States Food and Drug Administration (FDA) used a population-based definition (height SDS $<-2.25$ ) and otherwise highly interpretable criteria (open epiphyses, growth rate unlikely to result in normal adult height) that has reinforced the tendency to include CDGM and FSS under the rubric of ISS. It is remarkable that the treatment criterion of growth rate unlikely to result in normal adult height is missing from the consensus definition of ISS, an absence that allows for the odd inclusion of CDGM as a category of ISS [3].

FDA approval of the pharmacological (as opposed to the physiologic replacement in GHD) use of rhGH for a rather loosely defined ISS has reduced further the traditional adherence to the sequence of specific diagnosis dictating therapy. It has been in the marketing interest for $\mathrm{rhGH}$, and more recently for rhIGF-I, to promote expanded and vague definitions, or to introduce novel diagnoses $[9,10]$.

\section{Is ISS a Disease?}

The medical dictionary defines disease as, "a definite pathological process having a characteristic set of signs and symptoms. It may affect the whole body or any of its parts, and its etiology, pathology, and prognosis may be known or unknown" [11]. In an otherwise healthy child, short stature can only be considered "a pathological process" if there is, in fact, pathology justifying removal of the idiopathic descriptor, or if there are demonstrable handicapping effects.

The 2005 FDA and 2007 European Commission approvals of rhIGF-I for the treatment of rare GH insensitivity disorders (GH receptor deficiency, GH inactivating antibodies, defects in the GH activation pathway, and IGF-I mutations), unfortunately labeled with a novel and nonspecific diagnosis as "severe primary IGF-I deficiency (IGFD)" has opened the door for off-label trials based on the dubious finding of a single low IGF-I for age $[9,10]$. The promotion of IGF-I for treatment of ISS has focused on lower IGF-I levels in about half of such patients as an indication of "primary IGFD." As with GH testing, however, IGF-I determinations are unreliable for a variety of reasons: normal ranges vary; laboratories differ; there is high susceptibility to post sampling proteolysis; and levels can be low with undernutrition and ADHD medications, and with CDGM [12-14]. IGF-I generation tests have not been reliable or reproducible $[3,15]$. Perhaps most importantly, the data regarding lower circulating IGF-I concentrations in ISS are highly suspect because the populations studied include a majority of CDGM who have substantially delayed bone age and the IGF-I concentrations are interpreted for chronologic age. One would not expect a delayed 14-year-old boy with 4 cc testes and a bone age of 11 years (a typical presentation) to have a normal testosterone level for a 14-year-old. Similar logic should apply to interpreting IGF-I measurement, which is also developmental level dependent. In this example, an IGF-I concentration at $-2 \mathrm{SD}$ would become $-1 \mathrm{SD}$ when corrected for bone age.

While it may be intuitive that short stature is a handicap and, therefore, definable as a disease, neither history nor clinical research support this notion. Among notable literary, musical, and historical figures between -4 and -2 SDS are JM Barrie, Immanuel Kant, Jean-Paul Sartre, Edvard Greig, Napoleon, Voltaire, and Gandhi; others ranging from -7 to -3.5 SDS are noted in Table 1 [16]. Up until $\sim 15$ years ago, the conventional wisdom was that children with short stature were at risk for significant academic and social problems [17]. This view was based on clinical impressions from referred children and methodologically inadequate studies. Studies from England were the first to indirectly demonstrate referral bias, finding that normal children with short stature have unimpaired self-esteem 
and behavior, and normal IQ, but may underachieve and this was attributable to the association of shorter stature with lower socioeconomic status [18]. In a comparable US study, which included normal statured children as well as short referred and short nonreferred subjects, no differences were found in intelligence or achievement using teacher, parent, and child measures, but referred children had more externalizing behavior problems and poorer social skills, confirming referral bias [19]. Other studies have failed to show clinically significant psychosocial morbidity, school achievement or quality of life differences from normal among children referred for short stature [20-22]. Even among GHD patients, quality of life was unrelated to adult height and no different than same-sex unaffected siblings [23].

\section{Should ISS Be Treated?}

Commercial efforts attendant on the availability of rhGH starting in 1985 included various forms of supporting pediatric endocrinology programs, individual endocrinologists, and patient advocacy groups. The result was broadening of the definition of GHD and the range of conditions treated with rhGH, including the moving of many normal short children into rhGH treatable categories.

\section{Recombinant GH}

By definition, normal short stature does not require treatment for physical health benefits. Therefore, justification for growth enhancement therapy requires demonstration of individual or societal benefits, evidence of efficacy with absolute safety, and cost-benefit. Treatment of ISS with rhGH, as might be expected by the lack of definitive psychosocial problems attendant on short stature per se, has generally not been shown to affect school achievement, psychosocial measures, or quality-of-life when rhGH treated and untreated normal short children are compared [24-27].

Coincident with the absence of demonstrable individual or societal benefits of rhGH treatment of ISS, there is only modest evidence for efficacy, as might be expected when rhGH is being administered to non-GHD individuals [3]. With treatment for a period of $\sim 5$ years, $4-5 \mathrm{~cm}$ of added adult height can be expected, with wide individual variability. While it may be assumed that higher doses of rhGH, resulting in IGF-I levels comparable to those associated with growth promoting GH producing tumors would result in greater growth promotion, the potential for adverse metabolic and mitogenic side effects would not justify such an adventure. A recent meta-analysis of 10 randomized controlled trials of rhGH therapy in ISS found none of the studies to be of good quality and only two to be of moderate quality in terms of randomization methods, blinding, and the handling of withdrawals [28]. The conclusion from this analysis was "Although treated individuals may be taller than nontreated individuals, they are still relatively short compared with peers of normal height. Therefore, whether the small expected gain in height is substantial enough to merit frequent or daily injections for a number of years in children who do not have a disease is not clear. Additionally, there is no evidence that growth hormone treatment improves health related quality of life or psychological adaptation."

In the absence of evidence for individual or societal benefit, pharmacologic rhGH therapy for normal short stature does not appear cost beneficial. A mg of human rhGH costs $\sim 1000$ times as much as a mg of comparably produced bovine $\mathrm{GH}$, used for enhancing milk production. It has been estimated that the average cost of rhGH per inch $(2.5 \mathrm{~cm})$ of height attainment is US $\$ 52000$ [29]. Even if the price were to approximate actual value, there would still be costs for medical visits, IGF-I monitoring, parental work time lost, school absence, and injection supplies that would need to be justified. While failure to meet often unreal expectations and the effects of medicalizing otherwise healthy children might be considered a potential risk, recent data suggest stable psychological functioning in children with ISS receiving rhGH or placebo [27].

\section{Recombinant IGF-I}

The issue of pharmacological hormonal therapy for ISS has become further complicated by the intense off label promotion of rhIGF-I since 2005, based on the conjecture that most ISS is due to primary IGFD, which requires that clinicians, "Replace what's missing." The manufacturer has recruited clinicians to promote the egregious estimate of 60000 affected youngsters in the US and Europe [30] and to present case histories as indicative of patients who should receive IGF-I, but which do not meet approved criteria, and include straightforward CDGM [31]. As noted earlier, it is likely that the observation of reduced IGF-I concentrations in ISS is an artifact of erroneous analysis for chronologic rather than developmental (bone) age, if not a reflection of subtle undernutrition. The notion that IGF-I is a better growth promoter in ISS than is GH is without theoretical basis or clinical evidence over the three years that off-label use of rhIGF-I has been promoted. The absence of data regarding efficacy and safety of the use of IGF-I for treatment of ISS has been noted in the consensus report [3].

\section{Other Treatment Considerations}

Oxandrolone, a nonaromatizable synthetic androgen that can be administered orally, has been extensively studied in Turner syndrome and CDGM, and to supplement GH therapy in GHD and Turner syndrome [32]. Despite much anecdotal experience, there are no published data on its use in ISS. At low dosage $(\leq 0.1 \mathrm{mg} / \mathrm{kg} /$ day $)$ undue acceleration of osseous maturation with compromise of adult height does not occur; thus, consideration for ISS is not irrational. Aromatase inhibition, resulting in the interruption of the conversion of androgens to estrogen can delay osseous maturation, permitting a prolonged preadolescent growth period. Increased predicted adult height has been noted in boys with CDGM treated with aromatase inhibitor [33] and in boys with GHD treated with both rhGH and aromatase inhibition [34]. There are no data for ISS. 
TABLE 1: Short stature does not impede achievement.

\begin{tabular}{|c|c|c|}
\hline Name & Height & Accomplishments \\
\hline CP Steinmetz & $4^{\prime}(122 \mathrm{~cm})$ & $\begin{array}{l}\text { Electrical engineer whose ideas on alternating current systems helped inaugurate the electrical era } \\
\text { in the US }\end{array}$ \\
\hline Chick Web & $4^{\prime}(122)$ & Prominent bandleader and jazz drummer of the swing era \\
\hline Michael Ain & $4^{\prime} 3^{\prime \prime}(130)$ & Orthopedic surgeon-Johns Hopkins \\
\hline Benito Juarez & $4^{\prime} 6^{\prime \prime}(137)$ & National hero and president of Mexico from 1861 to 1863 and 1867 to 1872 \\
\hline Robert B. Reich & $4^{\prime} 9^{\prime \prime}(147)$ & $\begin{array}{l}\text { Professor of social and economic policy at Brandeis University. Secretary of labor in Pres. } \\
\text { Clinton's first term from 1993-1997 }\end{array}$ \\
\hline Andrew Carnegie & $5^{\prime}(152)$ & $\begin{array}{l}\text { Phenomenally successful entrepreneur- virtual founder of American steel industry and } \\
\text { philanthropist (Carnegie Mellon University, Carnegie Hall, libraries throughout US) }\end{array}$ \\
\hline David Ben Gurion & $5^{\prime}(152)$ & Founding Zionist and first prime minister of Israel \\
\hline Thomas Hart Benton & $5^{\prime}(152)$ & One of the foremost painters and muralists in 20th Century America \\
\hline
\end{tabular}

\section{Conclusion}

ISS is a diagnosis of exclusion and for clinical and counseling purposes needs to be considered distinct from CDGM and FSS. The most frequent reason for referral to pediatric endocrinologists, after diabetes management, is for evaluation and treatment of short stature. Most such children, who are predominately boys, have CDGM with height age comparable to bone age, indicating a normal adult height prognosis [35]. Such individuals, if they require treatment, can be given a three-month course of testosterone to accelerate adolescence without compromising final height, or a longer course of oxandrolone [3]. There is no rationale for treating this normal variation with rhGH on the basis of GH stimulation testing without sex steroid priming, and certainly not with rhIGF-I. FSS and ISS are characterized by deviant height for bone age and likelihood of adult short stature, which can be modestly, at best, altered by pharmacologic and costly rhGH treatment. There is no scientific rationale or evidence basis to suggest that rhIGFI would be more effective than rhGH in promoting growth in children with ISS, and reason to suspect that it might be counterproductive, suppressing endogenous GH effects on growing bone $[9,36]$. The recent consensus statement from the North American and European pediatric endocrinology societies notes the absence of evidence for psychosocial impact of short stature and the importance of discouraging the expectation that taller stature will improve quality of life [3].

\section{References}

[1] F. Lifshitz and D. Botero, "Worrisome growth," in Pediatric Endocrinology, F. Lifshitz, Ed., vol. 2, pp. 1-46, Marcel Dekker, New York, NY, USA, 5th edition, 2007.

[2] R. J. Kuszmarski, C. L. Ogden, L. M. Grummer-Strawn, et al., "CDC growth charts: United States. US Department of Health and Human Services, Centers for Disease Control and Prevention, National Center for Health Statistics," Advance Data, vol. 314, pp. 1-28, 2000.

[3] P. Cohen, A. D. Rogol, C. L. Deal, et al., "Consensus statement on the diagnosis and treatment of children with idiopathic short stature: a summary of the Growth Hormone Research
Society, the Lawson Wilkins Pediatric Endocrine Society, and the European Society for Paediatric Endocrinology Workshop," The Journal of Clinical Endocrinology \& Metabolism, vol. 93, no. 11, pp. 4210-4217, 2008.

[4] J. E. Abdenur, M. T. Pugliese, C. Cervantes, P. Fort, and F. Lifshitz, "Alterations in spontaneous growth hormone (GH) secretion and the response to GH-releasing hormone in children with nonorganic nutritional dwarfing," The Journal of Clinical Endocrinology \& Metabolism, vol. 75, no. 3, pp. 930934, 1992.

[5] M. B. Zimmermann, P. L. Jooste, N. S. Mabapa, et al., “Treatment of iodine deficiency in school-age children increases insulin-like growth factor (IGF)-I and IGF binding protein3 concentrations and improves somatic growth," The Journal of Clinical Endocrinology \& Metabolism, vol. 92, no. 2, pp. 437442, 2007.

[6] S. A. Wudy, S. Hagemann, A. Dempfle, et al., "Children with idiopathic short stature are poor eaters and have decreased body mass index," Pediatrics, vol. 116, no. 1, pp. e52-e57, 2005.

[7] G. Marin, H. M. Domene, K. M. Barnes, B. J. Blackwell, F. G. Cassorla, and G. B. Cutler Jr., "The effects of estrogen priming and puberty on the growth hormone response to standardize treadmill exercise and arginine insulin in normal girls and boys," The Journal of Clinical Endocrinology \& Metabolism, vol. 79, no. 2, pp. 537-541, 1994.

[8] M. Tauber, P. Moulin, C. Pienkowski, B. Jouret, and P. Rochiccioli, "Growth hormone (GH) retesting and auxological data in $131 \mathrm{GH}$-deficient patients after completion of treatment," The Journal of Clinical Endocrinology \& Metabolism, vol. 82, no. 2, pp. 352-356, 1997.

[9] A. L. Rosenbloom, "Is there a role for recombinant insulin-like growth factor-I in the treatment of idiopathic short stature?" The Lancet, vol. 368, no. 9535, pp. 612-616, 2006.

[10] A. L. Rosenbloom and J. Guevara-Aguirre, "Controversy in clinical endocrinology: reclassification of insulin-like growth factor I production and action disorders," The Journal of Clinical Endocrinology \& Metabolism, vol. 91, no. 11, pp. 42324234, 2006.

[11] W. A. Newman Dorland, Ed., Dorland's Illustrated Medical Dictionary, WB Saunders, Philadelphia, Pa, USA, 28th edition, 1994.

[12] D. Milani, J. D. Carmichael, J. Welkowitz, et al., "Variability and reliability of single serum IGF-I measurements: impact on determining predictability of risk ratios in disease development," The Journal of Clinical Endocrinology \& Metabolism, vol. 89, no. 5, pp. 2271-2274, 2004. 
[13] J. Khosravi, A. Diamandi, U. Bodani, N. Khaja, and R. G. Krishna, "Pitfalls of immunoassay and sample for IGF-I: comparison of different assay methodologies using various fresh and stored serum samples," Clinical Biochemistry, vol. 38, no. 7, pp. 659-666, 2005.

[14] J. C. Han, P. Balagopal, S. Sweeten, D. Darmaun, and N. Mauras, "Evidence for hypermetabolism in boys with constitutional delay of growth and maturation," The Journal of Clinical Endocrinology \& Metabolism, vol. 91, no. 6, pp. 20812086, 2006.

[15] A. A. Jorge, S. C. Souza, I. J. Arnhold, and B. B. Mendonca, "Poor reproducibility of IGF-I and IGF binding protein-3 generation test in children with short stature and normal coding region of the GH receptor gene," The Journal of Clinical Endocrinology \& Metabolism, vol. 87, no. 2, pp. 469-472, 2002.

[16] http://www.shortsupport.org/cgi-bin/whowho_list.cgi.

[17] B. Stabler, R. R. Clopper, P. T. Siegel, C. Stoppani, P. G. Compton, and L. E. Underwood, "Academic achievement and psychosocial adjustment in short children: the National Cooperative Growth Study," Journal of Developmental and Behavioral Pediatrics, vol. 15, pp. 1-6, 1994.

[18] A. B. Downie, J. Mulligan, R. J. Stratford, P. R. Betts, and L. D. Voss, "Are short normal children at a disadvantage? The Wessex growth study," British Medical Journal, vol. 314, no. 7074, pp. 97-100, 1997.

[19] J. H. Kranzler, A. L. Rosenbloom, B. Proctor, F. B. Diamond Jr., and M. Watson, "Is short stature a handicap? A comparison of the psychosocial functioning of referred and nonreferred children with normal short stature and children with normal stature," The Journal of Pediatrics, vol. 136, no. 1, pp. 96-102, 2000.

[20] J. Gilmour and D. Skuse, "Short stature-the role of intelligence in psychosocial adjustment," Archives of Disease in Childhood, vol. 75, no. 1, pp. 25-31, 1996.

[21] G. D. Zimet, R. Owens, W. Dohms, et al., "The psychosocial functioning of adults who were short as children," in Growth Stature, and Psychosocial Well-Being, F. Haverkamp and L. Voss, Eds., pp. 47-58, Hogrefe \& Huber, Seattle, Wash, USA, 1999.

[22] D. E. Sandberg, A. E. Brook, and S. P. Campos, "Short stature: a psychosocial burden requiring growth hormone therapy?" Pediatrics, vol. 94, no. 6, pp. 832-840, 1994.

[23] D. E. Sandberg, M. H. Macgillivray, R. R. Clopper, C. Fung, L. Leroux, and D. E. Alliger, "Quality of life among formerly treated childhood-onset growth hormone-deficient adults: a comparison with unaffected siblings," The Journal of Clinical Endocrinology \& Metabolism, vol. 83, no. 4, pp. 1134-1142, 1998.

[24] D. E. Sandberg and M. Colsman, "Growth hormone treatment of short stature: status of the quality of life rationale," Hormone Research, vol. 63, no. 6, pp. 275-283, 2005.

[25] D. Pilpel, E. Leiberman, Z. Zadik, and C. A. Carel, "Effect of growth hormone treatment on quality of life of short-stature children," Hormone Research, vol. 44, no. 1, pp. 1-5, 1995.

[26] N. C. M. Theunissen, G. A. Kamp, H. M. Koopman, K. A. H. Zwinderman, T. Vogels, and J.-M. Wit, "Quality of life and self-esteem in children treated for idiopathic short stature," Journal of Pediatrics, vol. 140, no. 5, pp. 507-515, 2002.

[27] J. L. Ross, D. E. Sandberg, S. R. Rose, et al., "Psychological adaptation in children with idiopathic short stature treated with growth hormone or placebo," The Journal of Clinical Endocrinology \& Metabolism, vol. 89, no. 10, pp. 4873-4878, 2004.
[28] J. Bryant, L. Baxter, C. B. Cave, and R. Milne, "Recombinant growth hormone for idiopathic short stature in children and adolescents," Cochrane Database of Systematic Reviews, vol. 18, no. 3, Article ID CD004440, pp. 1-37, 2007.

[29] J. M. Lee, M. M. Davis, S. J. Clark, T. P. Hofer, and A. R. Kemper, "Estimated cost-effectiveness of growth hormone therapy for idiopathic short stature," Archives of Pediatrics \& Adolescent Medicine, vol. 160, no. 3, pp. 263-269, 2006.

[30] http://www.shareholder.com/Common/Edgar/1262175/ 1193125-05-59908/05-00.pdf.

[31] J. Cohen, "The clinical impact of the GH IGF-I axis: a case study approach," Topics in Pediatric Endocrinology. Universal program number: \#816-999-07-046-H01-P. Medical Education Resources (supported by an unrestricted educational grant from Tercica Inc.) Unsolicited CD, September 2007.

[32] R. M. Blizzard, P. C. Hindmarsh, and R. Stanhope, "Oxandrolone therapy: 25 years experience," Growth Genetics and Hormones, vol. 7, pp. 1-6, 1991.

[33] M. Hero, S. Wickman, and L. Dunkel, "Treatment with the aromatase inhibitor letrozole during adolescence increases near-final height in boys with constitutional delay of puberty," Clinical Endocrinology, vol. 64, no. 5, pp. 510-513, 2006.

[34] N. Mauras, L. Gonzalez de Pijem, H. Y. Hsiang, et al., "Anastrozole increases predicted adult height of short adolescent males treated with growth hormone: a randomized, placebocontrolled, multicenter trial for one to three years," The Journal of Clinical Endocrinology \& Metabolism, vol. 93, no. 3, pp. 823-831, 2008.

[35] I. L. Sedlmeyer and M. R. Palmert, "Delayed puberty: analysis of a large case series from an academic center," The Journal of Clinical Endocrinology \& Metabolism, vol. 87, no. 4, pp. 16131620, 2002.

[36] O. G. Isaksson, A. Lindahl, A. Nilsson, and J. Isgaard, "Mechanism of the stimulatory effect of growth hormone on longitudinal bone growth," Endocrine Reviews, vol. 8, no. 4, pp. 426-438, 1987. 